\title{
Gastric Neuroendocrine Neoplasm
}

National Cancer Institute

\section{Source}

National Cancer Institute. Gastric Neuroendocrine Neoplasm. NCI Thesaurus. Code C5696.

A neoplasm with neuroendocrine differentiation that arises from the stomach. It includes well differentiated neuroendocrine tumors (low and intermediate grade) and poorly differentiated neuroendocrine carcinomas (high grade). 